Poor working conditions will put people off. If necessary, management must be fought to obtain improvements to the department, rest rooms, and so on. Use any influence you have to improve junior doctor accommodation, the doctor's mess, the catering, etc. Ensure good relationships with A\&E nursing staff and with other hospital departments.

SHOs are in training posts and it is important that they are taught well. Formal teaching is important and must be done in protected time with the department being covered by, for example, clinical assistants. Equally important is "bedside" teaching. Much learning in medicine comes from observing patient outcomes, but in A\&E there is a risk that one never hears what happens to the patients one treats. Encourage SHOs to follow patients up on the wards and ensure that they are given positive feedback and not just the negative feedback that comes when they make errors. Links with fracture clinic and obtaining discharge summaries of patients admitted may help. Encourage them to take study leave and try to ensure that local ALS or ATLS courses reserve places for your A\&E SHOs. A good boss can make all the difference to any job and you may need to improve your own performance. If necessary take advantage of courses on teaching methods, appraisal skills, and so on.

Ensure that the pay is right and that the ADHs paid reflect the fact that SHOs are expected to come to teaching sessions on their days off and may have late finishes as they stay on to sort out a difficult problem or to visit a ward to find out what happened to their patient.
There is no point having a perfect job if people do not know about it! Your best advertisement is your present and past SHOs, who will spread the word up and down the land, so treat them well. Try to attract medical students to your department, either on formal attachments or on electives-they may wish to return when qualified. Take every opportunity to teach house officers and medical students. Talk to them when they come into the department and encourage them to apply for your job. Advertise early while the pool of potential SHOs is still large. If you do get more suitable applicants than posts then, at interview, unsuccessful applicants can be offered a job for six months later.

The job will need to be formally advertised as well. There is a balance to be drawn between attracting attention with an interesting advertisement and putting people off with something too blatant ("what is the matter with the place if they have to advertise like that").

Once people have been attracted by the advertisement they will write for a job description. This is an official document with legal importance, but ensure that it shows the department in as good a light as possible. The hospital will probably also have promotional literature to send out to attract staff. Ensure that this is appropriate and well produced. In addition to the official job description, a prospectus to explain the way the department works and the experience that can be gained is also valuable .

H R GULY

Accident and Emergency Department, Derriford Hospital, Plymouth

\title{
The management series
}

The articles in the management series deal with common management issues faced by A\&E consultants. The authors are practising $A \& E$ consultants and a media specialist who have provided their way of addressing these issues. It is hoped that this series will contribute to the discussion of common management problems which we all face and need to be better prepared for.

To come:

- Dealing with the media $V O$ 'Loughlin

- How to appoint a senior house officer $H$ Guly

- How to conduct an SHO appraisal $M \mathcal{F}$ Clancy

- Organising training for undergraduates and SHOs

$N$ Rawlinson

- How to organise a higher training programme in $A \& E$

H Guly

- Managing a bed crisis $N$ Egan

- Time management $C$ McLauchlan
- Complaints-and how to deal with them G Bryce

- Risk management $H R$ Guly

- Purchasing new equipment $C D H$ Oakland

- Organising a medical conference $\mathcal{f}$ Wyatt

- Disciplinary procedures I P Stewart

- Choosing an A\&E department computer system $B C$ Elvin

- Dealing with the police $P A W H o w a r t h$ 